\title{
Cellular and Molecular Mechanisms of Retinal Ganglion Cell Death in Hypoxic-Ischemic Injuries
}

\author{
Charanjit Kaur ${ }^{1}$, Gurugirijha Rathnasamy ${ }^{1}$, Wallace S Foulds ${ }^{2}$ and Eng-Ang Ling ${ }^{1 *}$ \\ ${ }^{1}$ Department of Anatomy, Yong Loo Lin School of Medicine, Blk MD10, 4 Medical Drive, National University of Singapore, Singapore \\ ${ }^{2}$ Singapore Eye Research Institute, The Academia, 20 College Road, Discovery Tower Level 6, Singapore
}

Correspondence to:

Eng-Ang Ling, DSc

Department of Anatomy

Yong Loo Lin School of Medicine

Blk MD10, 4 Medical Drive

National University of Singapore, Singapore

Tel: 65-65163203

Fax: 65-67787643

E-mail: antlea@nus.edu.sg

Received: May 13, 2015

Accepted: Aug 06, 2015

Published: Aug 11, 2015

Citation: Kaur C, Rathnasamy G, Foulds WS, Ling EA. 2015. Cellular and Molecular Mechanisms of Retinal Ganglion Cell Death in Hypoxic-Ischemic Injuries. J Neurol Exp Neurosci 1(1): 10-19.

Copyright: (C) 2015 Kaur et al. This is an Open Access article distributed under the terms of the Creative Commons Attribution 4.0 International License (CC-BY) (http://creativecommons. org/licenses/by/4.0/) which permits commercial use, including reproduction, adaptation, and distribution of the article provided the original author and source are credited.

Published by United Scientific Group

\begin{abstract}
Loss of retinal ganglion cells (RGCs) occurs in retinal degenerative diseases, such as glaucoma, age-related macular degeneration, diabetic retinopathy, central retinal artery occlusion and ischemic central retinal vein thrombosis in adults and in retinopathy of prematurity in infants. A critical role of hypoxia, which underlies most of the above disorders, has been reported in causing RGC death. Disruption of blood-retinal barrier (BRB) occurs due to increased production of vascular endothelial growth factor and nitric oxide in response to hypoxia resulting in extravasation of serum derived substances and retinal edema and this may be one of important factors mediating RGC death. Activation of microglial cells in response to hypoxia and subsequent increased release of proinflammatory cytokines by them such as tumor-necrosis factor- $\alpha(\mathrm{TNF}-\alpha)$ and interleukin- $1 \beta$

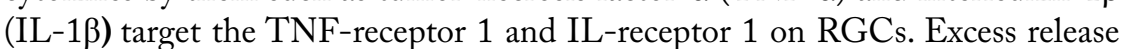
of glutamate in retinal tissue under hypoxia activates the ionotropic glutamate receptors causing excitotoxicity through increased influx of calcium into the RGCs. Increased production of TNF- $\alpha$, IL-1 $\beta$ and enhanced intracellular calcium results in RGC death through activating several pathways such as caspase signaling, mitochondrial dysfunction and oxidative stress. In our investigations, melatonin, an antioxidant, was shown to reduce RGC death in the adult and neonatal hypoxic retina, through suppression of TNF- $\alpha, \mathrm{IL}-1 \beta$ and glutamate levels as well as oxidative stress. Moreover, the function and structure of BRB was well preserved in these animals along with reduction in retinal edema. In view of our observations, we suggest that melatonin could be considered as a therapeutic agent to reduce RGC death in various retinal pathologies, in addition to other potential drugs/molecules of therapeutic interest that could render protection to RGCs. However, future in-depth research on the effects of melatonin on the retina under hypoxic conditions needs to be undertaken to explore its full potential in preventing/ameliorating RGC death.
\end{abstract}

\section{Keywords}

Retina, Retinal ganglion cell death, Hypoxia, Microglia, Inflammatory cytokines and other mediators, Oxidative stress

\section{Abbreviations}

AMPA: Amino-methyl-propionic-acid; BRB: Blood-retinal barrier; eNOS: Endothelial NOS; GSH: Glutathione; HRP: Horseradish peroxidase; HIF-1 $\alpha$ : Hypoxia inducible factor- $1 \alpha$; iNOS: Inducible NOS; IL-1R1: Interleukin receptor 1; IL-1 $\beta$ : Interleukin-1 $\beta$; LPO: Lipid peroxidation; MCP-1: Monocyte chemoattractant protein-1; nNOS: Neuronal NOS; 
NOS: Nitric oxide synthase; NMDA: $N$-methyl-d-aspartate; NO: Nitric oxide; NF-кB: Nuclear factor kappa B; ROS: Reactive oxygen species; RGC or RGCs: Retina ganglion cell or Retina ganglion cells; RhIC: Rhodamine isothiocynate; TJ: Tight junctions; TNF-R1: Tumor necrosis factor receptor 1 ; TNF- $\alpha$ : Tumor necrosis factor- $\alpha$; VEGFR1 (Flt-1): Vascular endothelial growth factor receptor 1; VEGFR2 (KDR/Flk-1): Vascular endothelial growth factor receptor 2; VEGF: Vascular endothelial growth factor; ZO-1: Zonula occludens-1

\section{Introduction}

The retina is one of the most metabolically active tissues and its demand for oxygen is higher than many other tissues including the brain [1-3]. Proper function of the retina depends on a continuous supply of oxygen which diffuses into it from circulation. The inner retina is supplied by capillary plexuses formed by branches of the central artery while the outer layers of the retina are nourished by the choriocapillaries. Deficient oxygen supply to the retina results in tissue hypoxia which is a critical factor implicated in retinal ganglion cell (RGC) death resulting in loss of vision in many ocular conditions such as retinal artery occlusion, ischemic central retinal vein thrombosis, glaucoma, diabetes $[4,5]$ and experimental branch retinal vein occlusion [6]. It may also result from systemic factors such as cardiorespiratory diseases. Chronic obstructive disease that is common among smokers is a significant cause of systemic and retinal hypoxia. In conditions such as the diabetes, occlusion of retinal capillaries by leukocytes and increased levels of endothelial cell/leukocyte adhesion molecules [7] reduce the retinal blood flow [8] and result in tissue hypoxia.

Normal development and maturation of many tissues including the retina are affected by either birth asphyxia (lack of oxygen in the blood stream), hypoxia (reduction in the available oxygen), ischemia (reduction in blood flow that could lead to hypoxia) or hypoxia-ischemia (decreased blood flow combined with a reduction in the supply of oxygen). Prenatal or fetal hypoxia can occur in association with many maternal causes such as diabetes, asthma, anemia, smoking and the use of alcohol or drugs. A reduction in utero-placental blood flow, premature onset of labour or prolonged labour may also compromise fetal oxygenation. Hypoxia may also result from respiratory distress syndrome in the premature new-born that may lead to development of retinopathy of prematurity. RGC death is known to occur following hypoxic injuries in the developing retina [9].

Several factors such as vascular endothelial growth factor (VEGF), nitric oxide (NO), inflammatory cytokines, glutamate and oxidative stress are up regulated or induced in response to hypoxia thus adversely affecting the structure and function of the retina. Additionally, vascular permeability is increased and the blood-retinal barrier $(\mathrm{BRB})$ is disrupted resulting in leakage of fluid into the retinal tissue. In diabetes, this may result in the development of diabetic macular edema, a leading cause of visual loss in diabetes [10]. Although various cells in the retina can be adversely affected by hypoxia, this review focuses on the death of the RGCs in hypoxia.

\section{Factors Mediating RGC Death}

Several factors induced or upregulated by hypoxia may be involved in causing RGC death. These factors include, among others, disruption of the blood-retinal barrier, activation of microglial cells and the accompanying enhanced release of inflammatory cytokines and excess release and accumulation of glutamate in the retinal tissues.

\section{Hypoxia and the blood-retinal barrier}

The BRB regulates the passage of molecules from blood into the retina $[11,12]$. It consists of an inner $\mathrm{BRB}$ formed by the tight junctions (TJ) between capillary endothelial cells and an outer barrier formed by TJ between retinal pigment epithelial cells [12-16]. The TJ are made up of transmembrane proteins such as occludin, claudin -5 and cytoplasmic proteins such as zona occludens ( $\mathrm{ZO})-1$ that are structurally and functionally important for maintaining the integrity of the BRB. The proper functioning of the inner BRB also requires the collective contribution of pericytes, Müller cells and astrocytes that are in close apposition to the capillary endothelial cells [16-19]. Moreover, disruption of the inner $\mathrm{BRB}$ results in vascular leakage resulting in the formation of edema [16, 20, 21] a well-recognized and early feature of human diabetic retinopathy $[22,23]$. BRB disruption due to hypoxia has also been reported to cause RGC swelling [6], endothelial cell death [24-27] and leukocyte plugging of vessels $[28,29]$. Associated with $\mathrm{BRB}$ disruption there is increased RGC death [30-32].

Hypoxic-ischemic insult to the adult retina, has been shown to affect the integrity of TJ by reducing the expression of ZO-1 and occludin. This alteration in the expression of TJ molecules was associated with increased BRB permeability and subsequent vasogenic edema [33]. Similar changes in the expression of TJ molecules were observed in the neonatal retina following a hypoxic injury [34]. Concomitant to the alterations in the expression of TJ molecules, the vascular permeability of the retinal vessels was enhanced, and was established by administering tracers such as horseradish peroxidase (HRP) intravenously or rhodamine isothiocynate (RhIC) intraperitoneally in hypoxic rats. An increased leakage of these tracers was observed through the blood vessels in the inner retina inundating the retinal tissues thereafter. These findings strongly imply that hypoxia results in BRB breakdown. In addition, the hyaloid vessels in the neonatal vitreous also showed increased permeability following hypoxic/ischemic injury [9].

Hypoxia induced disruption of inner BRB was further evident with the ultrastuctural analysis of both neonatal and adult hypoxic retina. In neonatal hypoxic retina, the basal lamina was disintegrated and the endothelial cells exhibited cytoplasmic vacuoles and swollen mitochondria. The capillaries were often surrounded by empty perivascular spaces suggesting the presence of edema [34]. The Müller cell and astrocyte processes surrounding the capillaries in the inner retina were found to be hypertrophic. Taken together all these structural changes indicate impairment in the integrity of BRB in hypoxic retina. Moreover, the expression of aquaporin 4, a water-transporting protein, was found to be increased in Müller cells and astrocytes indicating 
impairment in water and ion homeostasis that could lead to retinal edema [21]. The increased $\mathrm{BRB}$ permeability has been documented to alter the biochemical composition of retinal interstitial fluid [35] rendering the retinal microenvironment unbefitting for retinal cells. This could also compromise the neuron-glial communication [36] that serves to maintain retinal homeostasis. Of note, in transient retinal ischemia, the pertubation in Müller cell $\mathrm{K}^{+}$conductance could lead to retinal detachment [37] that could account for neuronal death in the retina. Although the molecular mechanisms underlying the BRB disruption and associated RGCs death has not been elucidated entirely, a few studies have highlighted the involvement of vasoactive substances such as VEGF and nitric oxide synthases (NOS) in these processes [29, 36, 38, 39].

The expression of hypoxia inducible factor- $1 \alpha(\mathrm{HIF}-1 \alpha)$, a master regulator of cellular and developmental $\mathrm{O}_{2}$ homeostasis that is induced by hypoxia, is known to induce the production of VEGF and nitric oxide synthase (NOS) in the neonatal and adult retina. In response to hypoxic injury, we have documented the increased production of VEGF and NO in the developing and adult retina $[21,9]$. The increased expression of VEGF in the retinal vessels is reported to cause the disruption of BRB following hypoxia [40-42], and an inhibition of VEGF has been shown to preserve the integrity of BRB [21]. In response to hypoxic injury, in adult and developing retina, VEGF was predominantly expressed in the astrocytes and Müller cells [21, 9]. VEGF exerts its action by binding to two tyrosine kinase receptors, VEGFR1 (Flt-1) and VEGFR2 (KDR/Flk-1). In neonatal hypoxic retina, the increased expression of Flt-1 and Flk-1 was localized on the vascular endothelium [43]. Activation of these receptors is known to cause disruption of TJ by decreasing the expression of occludin [44] and ZO-1 [45], and may be important in the pathogenesis of BRB dysfunction [44]. VEGF induced activation of Flk-1 is implicated in the increased vascular permeability/BRB breakdown, that occurs in diabetic retina [46]. Activation of Flt-1 has been shown to mediate pericyte loss in the retinal vasculature resulting in increased vascular leakage and retinal damage [47]. Moreover, VEGF is also known to induce fenestrations in endothelial cells [48-50] and degenerative changes in the basement membranes thus increasing the vascular permeability [51]. It enhances the adhesion of leucocytes to vascular wall by increasing intercellular cell adhesion molecule-1 (ICAM-1) and vascular cell adhesion molecule-expression $[29,52]$ on the endothelial cells resulting in capillary occlusion by adherent leukocytes, endothelial cell apoptosis and BRB breakdown $[26,29,53]$. Occlusion of blood vessels could further lead to increased production of angiogenic factors that could lead to neovascularisation and subsequent retinal detachment [38, 54]. Parallel to the BRB breakdown, recruitment of leukocytes and death of RGCs is frequently documented following an ischemic insult to the retina [30-32]. The entry of circulating leukocytes into the retina following $\mathrm{BRB}$ dysfunction is considered to play a critical role in RGC death [36]. The infiltrating leukocytes may activate the resident microglia that could result in death of RGCs and exacerbation of injury. Neufeld et al. [39] have documented that the infiltrating leukocytes could trigger RGC death through production of nitric oxide (NO). We have also documented an increased incidence of apoptotic RGCs and increased NO in the retinas of hypoxic animals [34].

$\mathrm{NO}$ is also reported to be involved in the breakdown of the BRB $[55,56]$. $\mathrm{NO}$ is primarily synthesized from $\mathrm{L}$-arginine by the NOS enzymes and is known to mediate neuronal communication as well vasodilatation. NOS from neurons (nNOS) and endothelial cells (eNOS) are constitutively expressed enzymes, the activities of which are calcium dependent, while inducible NOS (iNOS) is calcium-independent and NO generated from this isoform is known to mediate immune functions. Vasodilatation after hypoxic-ischaemic episodes is known to be caused by eNOS [57] resulting in increased blood flow in neural tissues. Investigations in retinas affected with diabetic retinopathy have thrown light on the mechanisms through which NOS could mediate $\mathrm{BRB}$ disruption. It has been suggested that $\mathrm{NO}$ from eNOS is involved in mediating VEGF-induced vascular hyperpermeability and NO produced by iNOS has an additive effect [58]. Joussen et al. [29] demonstrated that the increased production of VEGF could induce eNOS expression in the retina which could result in increased NO. NO derived from iNOS and eNOS was further found to facilitate BRB disruption by increasing ICAM-1 expression in the retinal endothelial cells which could promote leukocyte adhesion $[55,29]$. The potential of $\mathrm{NO}$ in mediating BRB breakdown was further evident with its ability to reduce the expression of TJ molecules such as ZO-1 and occludin [55]. NO is also known to interact with superoxides to form peroxynitrite which are highly toxic to all retinal cells including endothelial cells [55]. Our studies in the adult and neonatal retina following hypoxic injury have shown that eNOS expression in the retinal endothelial cells was significantly increased after hypoxic exposure [21, 9]. We also showed an induction of iNOS expression by hypoxia in the retinal blood vessels as well as in the RGCs. Concomitant to this, there was increased NO production in the hypoxic retina [9]. As discussed above the disruption of BRB could facilitate the infiltration of blood borne substances which could trigger microglial activation in the retina leading to excess production pro-inflammatory cytokines and excitatory amino acids [36] that could result in death of RGCs. Moreover, in vitro studies have shown that NO can disrupt TJ between retinal pigment epithelial cells [59]. However, in our studies in the adult and neonatal hypoxic animals, there was no evidence of disruption of the outer BRB.

Although VEGF has detrimental effects, it has also been reported to be important for the survival of RGCs in diabetic retina [60]. In cultured RGCs, the activation of VEGFR2 by VEGF-A conferred neuroprotection against free radicals through activation of AKT pathway [61]. VEGF-A is also documented to protect retinal neurons during the adaptive response to acute ischemia [62]. VEGF mediated cytoprotection is documented to involve glutathione, an antioxidant [63]. Given the complex contribution of VEGF in retinal diseases and injuries, and in protecting RGCs, future studies are warranted to delineate the isotypes mediating BRB disruption and cytoprotection. This could favour a holistic approach to the treatment of retinal diseases by preserving the retinal neurons. 


\section{Hypoxia and microglial activation}

Microglial cells are the resident immune effector cells in the retina. Under normal circumstances, they are confined to the nerve fibre layer, ganglion cell layer, inner and outer plexiform and inner nuclear layers in the adult retina $[64,65]$. However, under pathological conditions, they have been detected in the outer nuclear layer and in the subretinal space [66]. In the retina of newborns, microglial cells are found mostly in the nerve fibre and ganglion cell layers [67, 68]. Microglial cells have a phagocytic function during the early development of the retina where they remove cellular debris derived from spontaneous degenerating elements. They also act as sensors to detect any disturbances in the normal microenvironment. They have both neuroprotective and detrimental roles in the immature and mature retina. During development, microglia play an important role in scavenging cellular debris in the neural tissues [69, 70]. However, on activation in many pathological conditions they show increased production of noxious substances such as reactive oxygen species (ROS) and inflammatory cytokines [71].

Production of proinflammatory cytokines such as tumor necrosis factor- $\alpha(\mathrm{TNF}-\alpha)$ and interleukin-1 $\beta$ (IL-1 $\beta$ ) is known to be stimulated by hypoxia-ischemia in the retina $[67,72]$. It has been well documented that these cytokines are derived from microglial cells and participate in the breakdown of the BRB [73, 74] and in RGC death [67]. Activated microglia have been linked to diabetic and ischemic retinopathies in the adult $[66,75,76]$ and their numbers have been shown to increase in such conditions [77]. Microglial cells in the developing retina were the main source of TNF- $\alpha$ and IL-1 $\beta$, the expression levels of which were increased drastically in response to hypoxic exposures [67]. It is to be noted that RGCs were the target of these cytokines as they vigorously expressed TNF receptor 1 (TNF-R1) and IL receptor 1 (IL-1R1). TNF- $\alpha$ has been shown to mediate RGC death by binding with its receptor TNF-R1 in experimental elevation of intraocular pressure and in ocular conditions such as retinal ischemia, optic nerve crush and glaucoma [7880] RGC apoptosis occurs through this binding as a result of activation of caspase signaling pathways, mitochondrial dysfunction and oxidative damage [81].

Microglia derived IL-1 $\beta$ has been reported to augment brain damage in ischemic, traumatic or excitotoxic insults [8284] through depolarizing neurons. Our recent investigations have shown that increased release of IL-1 $\beta$ by retinal microglia and enhanced expression of IL-R1 on RGCs occurred concurrently in the retina of hypoxic neonatal rats. IL- $1 \beta$ can damage the RGCs by binding to its receptor IL-R1 and initiating mechanisms such as excitotoxicity and increased iNOS production through IL-R1 signalling [80].

Retinal hypoxia-ischemia is also known to induce the expression of monocyte chemoattractant protein-1 (MCP1) that attracts microglia and macrophages to the hypoxic areas resulting in aggravation of the inflammatory response [67]. MCP-1 expression has been suggested to attract resident macrophages/microglia, vitreous macrophages, and/or circulating monocytes through the $\mathrm{BRB}$ in the ischemic retina [76]. We have shown that MCP-1 expression was enhanced in the microglial cells in the hypoxic neonatal retina and this may be involved in attracting macrophages and inducing migration of microglia to the vicinity of RGCs. Increased numbers of microglia were indeed observed in the ganglion cell layer in the retinas of adult rats subjected to hypoxia. In vitro studies have lent further support to the involvement of microglia in hypoxia-induced RGC death. A significant reduction in RGC apoptosis was observed when they were treated with conditioned medium derived from primary microglia after neutralization with TNF- $\alpha$ and IL-1 $\beta$ antibodies. This suggests that hypoxia initiates retinal inflammation by direct activation of microglia with subsequent damage to RGCs [67]. In addition to the microglia, the hyalocytes, hyaloid and the retinal vessels showed enhanced expression of TNF- $\alpha$ and IL$1 \beta$ in the developing retina. It has also been reported that the vascular walls are a source of TNF- $\alpha$ production in the retina of diabetic patients [85] thus amplifying the inflammatory response of the microglial cells. TNF- $\alpha$ and other cytokines have also been documented to play a role in the development of vasogenic edema by inducing TJ disruption [86] and resulting in damage to the RGCs. Increased vascular permeability causes increased leakage of fluid and other potentially harmful molecules into the retina that would otherwise be excluded by an intact inner BRB.

\section{Hypoxia and glutamate}

Glutamate is the major excitatory neurotransmitter in the retina and is released by photoreceptors, bipolar neurons and RGCs $[87,88]$. Glutamate exerts its action through ionotropic [amino-methyl-propionic-acid (AMPA), N-methyl-daspartate (NMDA) and kainate GluRs] and metabotropic receptors $[89,90]$.It is also a potent neurotoxin involved in $\mathrm{RGC}$ death in hypoxic-ischemic conditions $[91,92]$ where increased accumulation of glutamate occurs in the extracellular spaces in the retinal tissue. Glutamate has been shown to affect the ganglion cell layer and also cause necrosis of cells in the inner retina [93]. Exposure of RGCs derived from newborn rats to glutamate resulted in induction of neurotoxicity [94]. Excess extracellular release of glutamate is known to kill neurons by excitotoxic mechanisms through activation the NMDA and AMPA receptors. Excitotoxicity has been suggested as a major mechanism underlying RGC death in many ocular pathologies including diabetic retinopathy, retinal and choroidal vessels occlusion and glaucoma [95-100]. Excitotoxic neuronal death involves calcium influx into the cells [101] that has been reported as an essential component of glutamate neurotoxicity [102]. Stimulation of glutamate receptors in chick RGCs in vitro caused calcium influx through NMDA receptorassociated channels and subsequently their death. Increased calcium influx in the neurons causes mitochondrial dysfunction and nNOS generation resulting in neuronal cell death [103, 104]. We have shown that expression of nNOS in the RGCs is enhanced in hypoxic injury and that hypoxic induction of nNOS is mediated by nuclear factor kappa B $(\mathrm{NF}-\kappa \mathrm{B})$. The increased amount of $\mathrm{NO}$ released subsequently, by RGCs, results in their apoptosis through caspase-3 activation [105]. Activation of NF- $\mathrm{NB}$ was demonstrated in the RGCs and was implicated in their apoptosis in the adult retina following optic nerve transection [106] and in hypoxia [107]; apoptosis of RGCs was prevented by administration of inhibitors for 
$\mathrm{NF}-\kappa \mathrm{B}$, such as parthenolide and sulfasalazine [108].

Recent studies in the hypoxic neonatal retina have shown upregulation of expression of various subunits of the NMDA receptor i.e. NR1 and NR2A-D and NR3A localized in the RGCs [109] and increased calcium influx in the hypoxic RGCs along with their augmented apoptosis. Apart from NMDA receptors, involvement of AMPA GluRs in hypoxicischemic cell death in the adult retina and neonatal retina has been reported [110]. AMPA receptors are composed of various combinations of four subunits (GluR 1-4), GluR1, GluR3 and GluR4 being calcium permeable, whereas the GluR2 subunit is calcium impermeable [111]. Accumulation of calcium in the mitochondria occurs with an increase in intracellular calcium and this calcium overload causes opening of the permeability transition pore resulting in massive swelling of the mitochondria and release of apoptotic mediators such as cytochrome $c[101,112,113]$. Mitochondrial failure results in energy depletion and free radical production [114].

Calcium influx through AMPA receptors and subsequent death of chick RGCs was shown to occur through stimulation of these receptors [115] and generation of free radicals such as superoxide through increased intracellular calcium has been reported. Activation of NOS leading to excess production of $\mathrm{NO}$ are also initiated by increased intracellular calcium and in ischemic conditions $\mathrm{NO}$ has been reported to produce peroxynitrite, which generates hydroxyl radical. The involvement of the NMDA and AMPA receptors in RGC death in hypoxic conditions is evidenced by significant attenuation in the intracellular calcium, cytochrome $c$, caspase- 3 and ROS in the hypoxic RGCs treated with NMDA receptor antagonist MK-801 [109] or AMPA receptor antagonist, 6, 7-dinitroquinoxaline-2,3-dione as reported by us [110].

\section{Hypoxia and oxidative stress}

The generation of free radicals derived from oxygen [ROS] is balanced in health as any excess is eliminated by endogenous antioxidants such as superoxide dismutase, catalase, glutathione peroxidase, glutathione (GSH) and others. Oxidative stress occurs in pathological conditions when the balance between free radical formation and the ability of endogenous antioxidants to eliminate them is disturbed. The disturbance in this balance damages the lipids, proteins, and DNA resulting in their oxidation and causing cell death by necrosis or apoptosis. It is well documented that hypoxia induces oxidative stress that plays a pivotal role in damaging the neurons in the adult and developing neural tissues [116120]. ROS has been reported to be involved in signaling RGC death by acting as a second messenger and/or modulating protein function in conditions such as glaucoma [121-123] and ischemic injuries of the retina [107, 124]. Hypoxia and oxidative stress are also involved in the development of diabetic retinopathy [125] resulting in RGC death [126]. Increased lipid peroxidation (LPO) and depletion of antioxidants such as GSH in response to hypoxia/reoxygenation have been reported by us to cause damage to RGCs [43]. Oxidative stress induces structural, biochemical, and functional abnormalities of mitochondria such as mitochondrial permeability transition pore opening and leakage of cytochrome $c$ from mitochondria into the cytosol in hypoxic conditions [109] contributing to cell injury or apoptosis and necrotic cell death [127-129]. Our studies on the neonatal retina have shown unequivocally that LPO was increased in the hypoxic retina while conversely, GSH levels were decreased along with increased apoptosis of RGCs thus underscoring the role of oxidative stress in RGC death [43].

Besides causing damage to the RGCs directly, oxidative stress has also been linked to the disruption of BRB in hypoxic-ischemic injuries and diabetic retinopathy [130]. ROS has been thought to contribute to the increased vascular permeability by causing TJ alterations through the enhanced production of inflammatory cytokines such as IL-1 $\beta$ and TNF- $\alpha$ and VEGF [130].

\section{Hypoxia and purinergic receptors}

The extracellular signalling by purine nucleotides and nucleosides, such as adenosine and adenosine tri phosphate (ATP) are now appreciated and the receptors through which they exert their action are called purinergic receptors. The purinergic receptors are further classified into three distinct classes P1 ( $A_{1}, A_{2 A}, A_{2 B}$ and $A_{3}$ for adenosine), P2X (P2X ligand gated ion channel receptors) and $\mathrm{P} 2 \mathrm{Y}$ receptors $\left(\mathrm{P} 2 \mathrm{Y}_{1-}\right.$ ${ }_{14}$ G-protein coupled purinoceptors) [131]. Purines along with their metabolites are known to contribute to a large number of functions in the eye including daily maintenance of ocular tissue and their dysregulated stimulation could contribute to ocular/retinal diseases involving death of RGCs [132]. The RGCs are known to express both $\mathrm{P} 1$ and $\mathrm{P} 2$ receptors [132]. While the information on the role of these receptors in RGCs are emerging, studies have focused on the activation of $\mathrm{P}_{2} \mathrm{X}_{7}$ receptor and associated $\mathrm{RGC}$ death. $\mathrm{P} 2 \mathrm{X}_{7}$ receptors expressed on RGCs are essential for modulating their synaptic responses [133]. While a short term stimulation of $\mathrm{P} 2 \mathrm{X}_{7}$ receptors induces physiological calcium response, prolonged stimulation is shown to mediate RGC death [134]. Under hypoxic/ ischemic conditions, activation of $\mathrm{P} 2 \mathrm{X}$ receptors, specifically the $\mathrm{P} 2 \mathrm{X}_{7}$ receptor, has been reported to cause death of RGCs $[134,135]$ by enhancing intracellular calcium levels. However, inhibition of $\mathrm{P}_{2} \mathrm{X}_{7}$ receptor prevented the death of RGCs following ischemic insult [135]. Taken together these studies provide compelling evidence for the involvement of $\mathrm{P}_{2} \mathrm{X}_{7}$ in RGCs death. Conversely, adenosine, that is accumulated following hypoxia, has been shown to confer protection to the RGCs by acting via the $A_{1}[136,137]$ and $A_{3}[138]$ receptors. Adenosine could also stimulate the $A_{2 A}$ receptors expressed on retinal vascular cells and induce VEGF production through cAMP-dependent protein kinase A pathway [139]. Given the complex role of VEGF in mediating $\mathrm{BRB}$ disruption and protecting RGC, in hypoxic conditions, it would be justifiable to state that purinergic receptors are also involved in this process and modulating their response would be of therapeutic interest.

\section{Protective effect of melatonin in hypoxia}

Melatonin, an indoleamine, is produced mainly by the pineal gland with some synthesis occurring in the retina also [140]. It is well established that melatonin has antioxidant properties [141] and has the ability to scavenge free radicals, induce expression of antioxidant enzymes and reduce lipid peroxidation to mitigate oxidative stress in neural tissues 
[142]. Hypoxia induced increase in lipid peroxidation in the retina was diminished and the reduced content of glutathione was increased in hypoxic rats treated with melatonin [43]. In addition to mitigating the oxidative stress, melatonin treatment was effective in significantly suppressing the TNF- $\alpha$ and IL$1 \beta$ levels in the retina of hypoxic rats thus mitigating hypoxiainduced inflammation. Suppression of the inflammatory response in ischemic conditions [143] and apoptosis in the developing hypoxic brain and retina $[142,43]$ by melatonin has been demonstrated. Very interestingly, melatonin was also effective in reducing the production of VEGF and NO and hypoxia-induced enhanced vascular permeability [9]. Reduced vascular permeability was evidenced by a reduction in extravasation of intraperitonially or intravenously administered RhIC and HRP into the retinas of hypoxic adult and neonatal rats $[21,9]$.

Mitochondrial damage is induced by hypoxia in a variety of cells in the retina including RGCs and Müller cells [109]. We have shown recently that hypoxia resulted in an increased release of cytochrome $c$ into the cytosol of RGCs as a result of opening of mitochondrial transition pores which activates cytosolic caspases such as caspase-3 [109]. Cytochrome c release and subsequent activation of caspase- 3 , which leads to apoptosis, were reduced in the RGCs following melatonin administration in the hypoxic retinas [43] and the occurrence of apoptotic RGCs was significantly reduced.

\section{Conclusion}

There is voluminous evidence that hypoxia is associated with many ocular pathologies and is a primary cause of death of RGCs. This may be mediated by different factors such as a disrupted BRB, excitotoxicity through increased extracellular glutamate levels and activation of NMDA and AMPA receptors, increased inflammation and oxidative stress (Figure 1). Therefore, mitigating RGC death would require therapies targeting the suppression of these factors.

We have shown that melatonin treatment of hypoxic animals has promising results in protecting the RGCs through suppression of inflammation, oxidative stress and

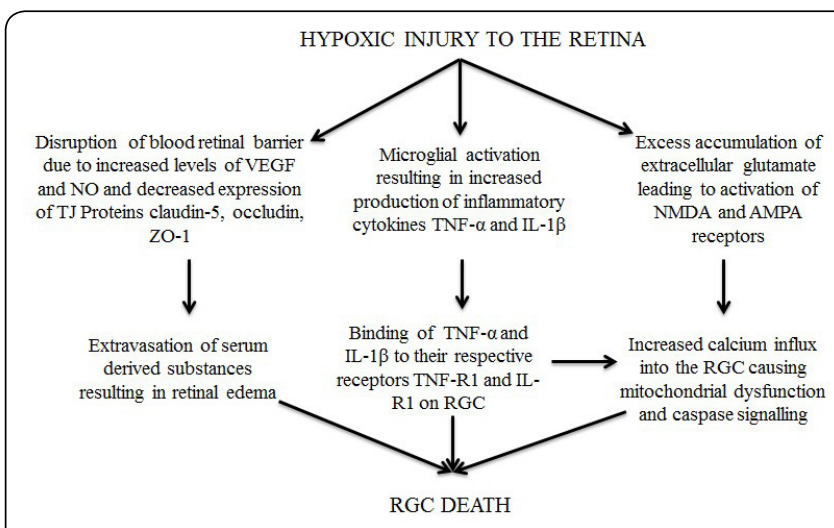

Figure 1: A schematic representation of the events occurring in the retina following a hypoxic injury which results in disruption of the blood-retinal barrier, increased production of proinflammatory cytokines by activated microglial cells and increased calcium influx into the RGCs through activated NMDA and AMPA receptors due to excess extracellular accumulation of glutamate. These events ultimately lead to RGC death in various ocular pathologies in which hypoxia plays a critical role. excitotoxic mediators as well as preserving the BRB. In view of its beneficial effects, we propose that melatonin could be considered as a potential therapeutic agent for the treatment of retinal pathologies in children and adults, in addition to other drugs/molecules of therapeutic interest. Future research on other beneficial properties of melatonin to identify its full neuroprotective potential in addition to its effectiveness in amelioration of oxidative stress and inflammation is certainly warranted.

\section{References}

1. Anderson B, Saltzman HA. 1964. Retinal oxygen utilization measured by hyperbaric blackout. Arch Ophthalmol 72(6): 792-795. doi: 10.1001/ archopht.1964.00970020794009

2. Cohen LH, Noell WK. 1965. Relationships between visual function and metabolism. In: Graymore CN, editor. Biochemistry of the Retina. Orlando, FL, USA: Academic Press Inc 36-50.

3. Ames A. 1992. Energy requirements of CNS cells as related to their function and to their vulnerability to ischemia: a commentary based on studies on retina. Can J Physiol Pharmacol 70(Suppl): S158-164. doi: $10.1139 /$ y92-257

4. Sucher NJ, Lipton SA, Dreyer EB. 1997. Molecular basis of glutamate toxicity in retinal ganglion cells. Vision Res 37(24): 3483-3493. doi: 10.1016/S0042-6989(97)00047-3

5. Abu-El-Asrar AM, Dralands L, Missotten L, Al-Jadaan IA, Geboes K. 2004. Expression of apoptosis markers in the retinas of human subjects with diabetes. Invest Ophthalmol Vis Sci 45(8): 2760-2766. doi: 10.1167/ iovs.03-1392

6. Donati G, Pournaras CJ, Pizzolato GP, Tsacopoulos M. 1997. Decreased nitric oxide production accounts for secondary arteriolar constriction after retinal branch vein occlusion. Invest Ophthalmol Vis Sci 38(7): 1450-1457.

7. McLeod DS, Lefer DJ, Merges C, Lutty GA. 1995. Enhanced expression of intracellular adhesion molecule-1 and P-selectin in the diabetic retina and choroid. Am J Pathol 147(3): 642-653.

8. Rimmer T, Fallon TJ, Kohner EM. 1989. Long-term follow-up of retinal blood flow in diabetes using the blue light entoptic phenomenon. BrJ Ophthalmol 73(1): 1-5. doi: 10.1136/bjo.73.1.1

9. Kaur C, Sivakumar V, Foulds WS, Luu CD, Ling EA. 2009. Cellular and vascular changes in the retina of neonatal rats following an acute exposure to hypoxia. Invest Ophthalmol Vis Sci 50(11): 5364-5374. doi: 10.1167/iovs.09-3552

10. Petrella RJ, Blouin J, Davies B, Barbeau M. 2012. Prevalence, Demographics, and Treatment Characteristics of Visual Impairment due to Diabetic Macular Edema in a Representative Canadian Cohort. J Ophthalmol 2012: 159167. doi: 10.1155/2012/159167

11. Tornquist P, Alm A, Bill A. 1990. Permeability of ocular vessels and transport across the blood-retinal-barrier. Eye (Lond) 4(pt 2): 303-309. doi: 10.1038/eye.1990.41

12. Vinores SA. 1995. Assessment of blood-retinal barrier integrity. Histol Histopathol 10(1): 141-154

13. Bill A, Tornquist P, Alm A. 1980. Permeability of the intraocular blood vessels. Trans Ophthalmol Soc UK 100(3): 332-336.

14. Cunha-Vaz JG. 1976. The blood-retinal barriers. Doc Ophthalmol 41(2): 287-327. doi: 10.1007/BF00146764

15. Cunha-Vaz JG. 1980. Blood-retinal barriers in health and disease. Trans Ophthalmol Soc UK 100(3): 337-340.

16. Kaur C, Foulds WS, Ling EA. 2008. Blood retinal barrier in hypoxic ischaemic conditions: basic concepts, clinical features and management. Prog Retin Eye Res 27(6): 622-647. doi: 10.1016/j. preteyeres.2008.09.003

17. Ashton N. 1965. The blood-retinal barrier and vaso-glial relationships in retinal disease. Trans Ophthal Soc U K 85:199-230. 
18. Cunha-Vaz JG, Shakib N, Ashton N. 1966. Studies on the permeability of the blood-retinal barrier. I. On the existence, development, and site of a blood-retinal barrier. Br J Ophthalmol 50(8): 441-453. doi: 10.1136/ bjo.50.8.441

19. Hollander H, Makarov F, Dreher Z, van Driel D, Chan-Ling TL, et al. 1991. Structure of the macroglia of the retina: sharing and division of labour between astrocytes and Muller cells. J Comp Neurol 313(4): 587603. doi: $10.1002 /$ cne. 903130405

20. Pannicke T, Iandiev I, Wurm A, Uckermann O, Vom Hagen F, et al. 2006. Diabetes alters osmotic swelling characteristics and membrane conductance of glial cells in rat retina. Diabetes 55(3): 633-639. doi: 10.2337/diabetes.55.03.06.db05-1349

21. Kaur C, Sivakumar V, Zhang Y, Lu J, Foulds WS, et al. 2007. Bloodretinal barrier disruption and ultrastuctural changes in the hypoxic retina in adult rats: The beneficial effect of melatonin administration. $J$ Pathol 212(4): 429-439. doi: 10.1002/path.2195

22. Norton EW, Gutman F. 1967. In Vascular Complications of Diabetes Mellitis, Kimura SJ and Caygill WM Eds. Mosby, St Louis, USA, pp 120-136.

23. Cuhna-Vaz J, Fariade Abreu JR, Campos AJ, Figo GM. 1975. Early breakdown in the blood-retinal barrier in diabetes. $\mathrm{Br} J$ Ophthalmol 59(11): 449-456. doi: 10.1136/bjo.59.11.649

24. Ashton N. 1963. Studies of the retinal capillaries in relation to diabetic and other retinopathies. Brit J Ophthalmol 47(9): 521-538. doi: 10.1136/ bjo.47.9.521

25. Sharma NK, Gardiner TA, Archer DB. 1985. A morphologic and autoradiographic study of cell death and regeneration in the retinal microvasculature of normal and diabetic rats. Am J Ophthalmol 100(1): 51-60. doi: 10.1016/S0002-9394(14)74982-7

26. Joussen AM, Murata T, Tsujikawa A, Kirchhof B, Bursell SE, et al. 2001. Leukocyte-mediated endothelial cell injury and death in the diabetic retina. Am J Pathol 158(1): 147-152. doi: 10.1016/S00029440(10)63952-1

27. Kowluru RA. 2005. Diabetic retinopathy: mitochondrial dysfunction and retinal capillary cell death. Antioxid Redox Signal 7(11-12): 15811587. doi: 10.1089/ars.2005.7.1581

28. Linsenmeier RA, Braun RD, McRipley MA, Padnick LB, Ahmed J, et al. 1998. Retinal hypoxia in long-term diabetic cats. Invest Ophthalmol Vis Sci 39(9): 1647-1657.

29. Joussen AM, Poulaki V, Qin W, Kirchhof B, Mitsiades N, et al. 2002. Retinal vascular endothelial growth factor induces intercellular adhesion molecule- 1 and endothelial nitric oxide synthase expression and initiates early diabetic retinal leukocyte adhesion in vivo. $\mathrm{Am} \mathrm{J}$ Pathol 160(2): 501-509. doi: 10.1016/S0002-9440(10)64869-9

30. He M, Pan H, Chang RC, So KF, Brecha NC, et al. 2014. Activation of the Nrf2/HO-1 antioxidant pathway contributes to the protective effects of Lycium barbarum polysaccharides in the rodent retina after ischemia-reperfusion-induced damage. PLoS One 9(1): e84800. doi: 10.1371/journal.pone.0084800

31. Sun MH, Pang JH, Chen SL, Han WH, Ho TC, et al. 2010. Retinal protection from acute glaucoma-induced ischemia-reperfusion injury through pharmacologic induction of heme oxygenase-1. Invest Ophthalmol Vis Sci 51(9): 4798-4808. doi: 10.1167/iovs.09-4086

32. Ju WK, Kim KY, Neufeld AH. 2003. Increased activity of cyclooxygenase-2 signals early neurodegenerative events in the rat retina following transient ischemia. Exp Eye Res 77(2): 137-145. doi: 10.1016/S0014-4835(03)00128-3

33. Tong N, Zhang Z, Zhang W, Qiu Y, Gong Y, et al. 2013. Diosmin alleviates retinal edema by protecting the blood-retinal barrier and reducing retinal vascular permeability during ischemia/reperfusion injury. PloS one 8(4): e61794. doi: 10.1371/journal.pone.0061794

34. Rathnasamy G, Sivakumar V, Foulds WS, Ling EA, Kaur C. 2015. Vascular changes in the developing rat retina in response to hypoxia. Exp Eye Res 130: 73-86. doi: 10.1016/j.exer.2014.11.011

35. Clermont A, Chilcote TJ, Kita T, Liu J, Riva P, et al. 2011. Plasma
Kallikrein Mediates Retinal Vascular Dysfunction and Induces Retinal Thickening in Diabetic Rats. Diabetes 60(5): 1590-1598. doi: 10.2337/ db10-1260

36. Antonetti DA, Barber AJ, Bronson SK, Freeman WM, Gardner TW, et al. 2006. Diabetic retinopathy: seeing beyond glucose-induced microvascular disease. Diabetes 55(9): 2401-2411. doi: 10.2337/db051635

37. Uckermann O, Kutzera F, Wolf A, Pannicke T, Reichenbach A, et al. 2005. The glucocorticoid triamcinolone acetonide inhibits osmotic swelling of retinal glial cells via stimulation of endogenous adenosine signaling. J Pharmacol Exp Ther 315(3): 1036-1045. doi: 10.1124/ jpet.105.092353.

38. Miller JW, Adamis AP, Aiello LP. 1997. Vascular endothelial growth factor in ocular neovascularization and proliferative diabetic retinopathy. Diabetes Metab Rev 13(1): 37-50. doi: 10.1002/(SICI)10990895(199703)13:1<37::AID-DMR174>3.0.CO;2-K

39. Neufeld AH, Kawai Si, Das S, Vora S, Gachie E, et al. 2002. Loss of retinal ganglion cells following retinal ischemia: the role of inducible nitric oxide synthase. Exp Eye Res 75(5): 521-528. doi: 10.1006/ exer.2002.2042

40. Murata T,IshibashiT, Khalil A,Hata Y,Yoshikawa H et al.1995. Vascular endothelial growth factor plays a role in hyperpermeability of diabetic retinal vessels. Ophthalmic Res 27(1): 48-52. doi: 10.1159/000267567

41. Miyamoto K, Khosrof S, Bursell S-E, Moromizato Y, Aiello LP, et al. 2000. Vascular endothelial growth factor (VEGF)-induced retinal vascular permeability is mediated by intercellular adhesion molecule-1 (ICAM-1). Am J Path 156(5): 1733-1739. doi: 10.1016/S00029440(10)65044-4

42. Zhang ZG, Zhang L, Tsang W, Soltanian-Zadeh H, Morris D, et al. 2002. Correlation of VEGF and angiopoietin expression with disruption of blood-brain barrier and angiogenesis after focal cerebral ischemia. J Cereb Blood Flow Metab 22(4): 379-392. doi: 10.1097/00004647200204000-00002

43. Kaur C, Sivakumar V, Robinson R, Foulds WS, Luu CD, et al. 2013. Neuroprotective effect of melatonin against hypoxia-induced retinal ganglion cell death in neonatal rats. J Pineal Res 54(2): 190-206. doi: 10.1111/jpi.12016

44. Spoerri PE, Afzal A, Li Calzi S, Shaw LC, Cai J, et al. 2006. Effects of VEGFR-1, VEGFR-2, and IGF-IR hammerhead ribozymes on glucose-mediated tight junction expression in cultured human retinal endothelial cells. Mol Vis 12: 32-42.

45. Fischer S, Wobben M, Marti HH, Renz D, Schaper W. 2002. Hypoxia-induced hyperpermeability in brain microvessel endothelial cells involves VEGF-mediated changes in the expression of zonula occludens-1. Microvasc Res 63(1): 70-80. doi: 10.1006/mvre.2001.2367

46. Zhang X, Bao S, Lai D, Rapkins RW, Gillies MC. 2008. Intravitreal triamcinolone acetonide inhibits breakdown of the blood-retinal barrier through differential regulation of VEGF-A and its receptors in early diabetic rat retinas. Diabetes 57(4): 1026-1033. doi: 10.2337/db07-0982

47. Cao R, Xue Y, Hedlund EM, Zhong Z, Tritsaris K, et al. 2010. VEGFR1-mediated pericyte ablation links VEGF and P1GF to cancer-associated retinopathy. Proc Natl Acad Sci USA 107(2): 856-861. doi: 10.1073/pnas.0911661107

48. Roberts WG, Palade GE. 1995. Increased microvascular permeability and endothelial fenestration induced by vascular endothelial growth factor. J Cell Sci 108 (Pt 6): 2369-2379.

49. Roberts WG, Palade GE. 1997. Neovasculature induced by vascular endothelial growth factor is fenestrated. Cancer Res 57(4): 765-772.

50. Esser S, Wolburg K, Wolburg H, Breier G, Kurzchalia T, et al. 1998. Vascular endothelial growth factor induces endothelial fenestrations in vitro. J Cell Biol 140(4): 947-959. doi: 10.1083/jcb.140.4.947

51. Dobrogowska DH, Lossinsky AS, Tarnawski M, Vorbrodt AW. 1998. Increased blood-brain barrier permeability and endothelial abnormalities induced by vascular endothelial growth factor.J Neurocytol 27(3): 163-173. doi: 10.1023/A:1006907608230 
52. Min JK, Kim YM, Kim SW, Kwon MC, Kong YY, et al. 2005. TNFrelated activation-induced cytokine enhances leukocyte adhesiveness: induction of ICAM-1 and VCAM-1 via TNF receptor-associated factor and protein kinase $\mathrm{C}$-dependent NF-kappaB activation in endothelial cells. J Immunol 175(1): 531-540. doi: 10.4049/jimmunol.175.1.531

53. Miyamoto K, Khosrof S, Bursell SE, Rohan R, Murata T, et al. 1999. Prevention of leukostasis and vascular leakage in streptozotocininduced diabetic retinopathy via intercellular adhesion molecule-1 inhibition. Proc Natl Acad Sci U S A 96(19): 10836-10841. doi: 10.1073/ pnas.96.19.10836

54. Ciulla TA, Amador AG, Zinman B. 2003. Diabetic retinopathy and diabetic macular edema: pathophysiology, screening, and novel therapies. Diabetes Care 26(9): 2653-2664. doi: 10.2337/diacare.26.9.2653

55. Leal EC, Manivannan A, Hosoya K, Terasaki T, Cunha-Vaz J, et al. 2007. Inducible nitric oxide synthase isoform is a key mediator of leukostasis and blood-retinal barrier breakdown in diabetic retinopathy. Invest Ophthalmol Vis Sci 48(11): 5257-5265. doi: 10.1167/iovs.07-0112

56. Carmo A, Cunha-Vaz JG, Carvalho AP, Lopes MC. 2000. Nitric oxide synthase activity in retinas from non-insulin-dependent diabetic GotoKakizaki rats: correlation with blood-retinal barrier permeability. Nitric Oxide 4(6): 590-596. doi:10.1006/niox.2000.0312

57. Bolanos JP, Almeida A. 1999. Roles of nitric oxide in brain hypoxiaischemia. Biochim Biophys Acta 1411(2-3): 415-436. doi: 10.1016/ S0005-2728(99)00030-4

58. Fukumura D, Gohongi T, Kadambi A, Izumi Y, Ang J, et al. 2001. Predominant role of endothelial nitric oxide synthase in vascular endothelial growth factor-induced angiogenesis and vascular permeability. Proc Natl Acad Sci U S A 98(5): 2604-2609. doi: 10.1073/ pnas.041359198

59. Zech JC, Pouvreau I, Cotinet A, Goureau O, Le Varlet B, et al. 1998 Effect of cytokines and nitric oxide on tight junctions in rat cultured pigment epithelium. Invest Ophthal Vis Sci 39(9): 1600-1608.

60. Park HY, Kim JH, Park CK. 2014. Neuronal cell death in the inner retina and the influence of vascular endothelial growth factor inhibition in a diabetic rat model. Am J Pathol 184(6): 1752-1762. doi: 10.1016/j. ajpath.2014.02.016

61. Foxton RH, Finkelstein A, Vijay S, Dahlmann-Noor A, Khaw PT, et al 2013. VEGF-A is necessary and sufficient for retinal neuroprotection in models of experimental glaucoma. Am J Pathol 182(4): 1379-1390. doi: 10.1016/j.ajpath.2012.12.032

62. Nishijima K,NgYS,Zhong L,BradleyJ, SchubertW,et al.2007. Vascular endothelial growth factor-A is a survival factor for retinal neurons and a critical neuroprotectant during the adaptive response to ischemic injury. Am J Pathol 171(1): 53-67. doi: 10.2353/ajpath.2007.061237

63. Brar VS, Sharma RK, Murthy RK, Chalam KV. 2010. Bevacizumab neutralizes the protective effect of vascular endothelial growth factor on retinal ganglion cells. Mol Vis 16: 1848-1853.

64. Santos AM, Calvente R, Tassi M, Carrasco MC, Martín-Oliva D, et al. 2008. Embryonic and postnatal development of microglial cells in the mouse retina. J Comp Neurol 506(2): 224-239. doi: 10.1002/cne.21538

65. Ling EA. 1982. A light microscopic demonstration of amoeboid microglia and microglial cells in the retina of rats of various ages. Arch Histol Jpn 45(1): 37-44. doi: 10.1679/aohc.45.37

66. Zeng XX, Ng YK, Ling EA. 2000. Neuronal and microglial response in the retina of streptozotocin-induced diabetic rats. Vis Neurosci 17(3): 463-471.

67. Sivakumar V, Foulds WS, Luu CD, Ling EA, Kaur C. 2011. Retinal ganglion cell death is induced by microglia derived proinflammatory cytokines in the hypoxic neonatal retina. Journal of Pathology 224(2): 245-260. doi: $10.1002 /$ path. 2858

68. Rivera JC, Sitaras N, Noueihed B, Hamel D, Madaan A, et al. 2013. Microglia and interleukin- $1 \beta$ in ischemic retinopathy elicit microvascular degeneration through neuronal semaphorin-3A. Arterioscler Thromb Vasc Biol 33(8): 1881-1891. doi: 10.1161/ATVBAHA.113.301331

69. Hume DA, Perry VH, Gordon S. 1983. Immunohistochemical localization of a macrophage-specific antigen in developing mouse retina: phagocytosis of dying neurons and differentiation of microglial cells to form a regular array in the plexiform layers. J Cell Biol 97(1): 253-257. doi: $10.1083 /$ jcb. 97.1 .253

70. Egensperger R, Maslim J, Bisti S, Holländer H, Stone J. 1996. Fate of DNA from retinal cells dying during development: uptake by microglia and macroglia (Müller cells). Brain Res Dev Brain Res 97(1): 1-8. doi: 10.1016/S0165-3806(96)00119-8

71. Dheen ST, Kaur C, Ling EA. 2007. Microglial activation and its implications in the brain diseases. Curr Med Chem 14(11): 1189-1197. doi: 10.2174/092986707780597961

72. Yoshida S, Yoshida A, Ishibashi T. 2004. Induction of IL-8, MCP-1, and bFGF by TNF-alpha in retinal glial cells: implications for retinal neovascularization during post-ischemic inflammation. Graefes Arch Clin Exp Ophthalmol 242(5): 409-413. doi: 10.1007/s00417-004-0874-2

73. Martiney JA, Litwak M, Berman JW, Arezzo JC, Brosnan CF. 1990. Pathophysiologic effect of interleukin-1b in the rabbit retina. Am J Pathol 137(6): 1411-1423.

74. Luna JD, Chan CC, Derevjanik NL, Mahlow J, Chiu C, et al. 1997. Blood-retinal barrier (BRB) breakdown in experimental autoimmune uveoretinitis: comparison with vascular endothelial growth factor, tumor necrosis factor alpha, and interleukin-1beta-mediated breakdown. J Neurosci Res 49(3): 268-280. doi: 10.1002/(SICI)10974547(19970801)49:3<268::AID-JNR2>3.0.CO;2-A

75. Rungger-Brändle E, Dosso AA, Leuenberger PM. 2000. Glial reactivity, an early feature of diabetic retinopathy. Invest Ophthalmol Vis Sci 41(7): 1971-1980.

76. Yoshida S, Yoshida A, Ishibashi T, Elner SG, Elner VM. 2003. Role of MCP-1 and MIP-1alpha in retinal neovascularization during postischemic inflammation in a mouse model of retinal neovascularization. J Leukoc Biol 73(1): 137-144. doi: 10.1189/ jlb.0302117

77. Davies MH,Eubanks JP, Powers MR. 2006. Microglia and macrophages are increased in response to ischemia-induced retinopathy in the mouse retina. Mol Vis 12: 467-477.

78. Tezel G, Li LY, Patil RV, Wax MB. 2001. TNF-alpha and TNFalpha receptor-1 in the retina of normal and glaucomatous eyes. Invest Ophthalmol Vis Sci 42(8): 1787-1794.

79. Tezel G, Yang X, Yang J, Wax MB. 2004. Role of tumor necrosis factor receptor-1 in the death of retinal ganglion cells following optic nerve crush injury in mice. Brain Res 996(2): 202-212. doi: 10.1016/j. brainres.2003.10.029

80. MaXC, Gottschall PE, Chen LT,Wiranowska M, Phelps CP.2002. Role and mechanisms of interleukin-1 in the modulation of neurotoxicity. Neuroimmunomodulation 10(4): 199-207. doi: 10.1159/000068322

81. Nakazawa T, Nakazawa C, Matsubara A, Noda K, Hisatomi T, et al. 2006. Tumor necrosis factor-alpha mediates oligodendrocyte death and delayed retinal ganglion cell loss in a mouse model of glaucoma.JNeurosci 26(49): 12633-12641. doi: 10.1523/JNEUROSCI.2801-06.2006

82. Lawrence CB, Allan SM, Rothwell NJ. 1998. Interleukin-1beta and the interleukin-1 receptor antagonist act in the striatum to modify excitotoxic brain damage in the rat. Eur J Neurosci 10(3): 1188-1195. doi: 10.1046/j.1460-9568.1998.00136.x

83. Davies CA, Loddick SA, Toulmond S, Stroemer RP, Hunt J, et al. 1999. The progression and topographic distribution of interleukin-1beta expression after permanent middle cerebral artery occlusion in the rat. J Cereb Blood Flow Metab 19(1): 87-98. doi: 10.1097/00004647199901000-00010

84. Boutin H, LeFeuvre RA, Horai R, Asano M, Iwakura Y, et al. 2001. Role of IL-1alpha and IL-1beta in ischemic brain damage. J Neurosci 21(15): 5528-5534.

85. Limb GA, Chignell AH, Green W, LeRoy F, Dumonde DC. 1996. Distribution of TNF alpha and its reactive vascular adhesion molecules in fibrovascular membranes of proliferative diabetic retinopathy. $\mathrm{BrJ}$ Ophthalmol 80(2): 168-173. doi: 10.1136/bjo.80.2.168 
86. Lv S, Song HL, Zhou Y, Li LX, Cui W, et al. 2010. Tumour necrosis factor-alpha affects blood-brain barrier permeability and tight junctionassociated occludin in acute liver failure. Liver Int 30(8): 1198-1210. doi: 10.1111/j.1478-3231.2010.02211.x

87. Lam DM. 1997. Neurotransmitters in the vertebrate retina. Invest Ophthalmol Vis Sci 38(3): 553-556.

88. Pow DV. 2001. Amino acids and their transporters in the retina Neurochem Int 38(6): 463-484. doi: 10.1016/S0197-0186(00)00114-5

89. Brandstätter JH, Koulen P, Wässle H. 1998. Diversity of glutamate receptors in the mammalian retina. Vision Res 38: 1385-1397. doi: 10.1016/S0042-6989(97)00176-4

90. Gründer T, Kohler K, Guenthe E. 2001. Alterations in NMDA receptor expression during retinal degeneration in the RCS rat. Vis Neurosci 18(5): 781-787. doi: 10.1017/S0952523801185111

91. Adachi K, Kashii S, Masai H, Ueda M, Morizane C, et al. 1998. Mechanism of the pathogenesis of glutamate neurotoxicity in retinal ischemia. Graefes Arch Clin Exp Ophthalmol 236(10): 766-774. doi: 10.1007/s004170050156

92. Nucci C, Tartaglione R, Rombola L, Morrone LA, Fazzi E, et al. 2005. Neurochemical evidence to implicate elevated glutamate in the mechanisms of high intraocular pressure (IOP)-induced retinal ganglion cell death in rat. Neurotoxicology 26(5): 935-941. doi: 10.1016/j.neuro.2005.06.002

93. Olney JW. 1982. The toxic effects of glutamate and related compounds in the retina and the brain. Retina 2(4): 341-359.

94. Yoneda S, Tanaka E, Goto W, Ota T, Hara H. 2003. Topiramate reduces excitotoxic and ischemic injury in the rat retina. Brain Res $967(1-2)$ 257-266. doi: 10.1016/S0006-8993(03)02270-4

95. Osborne NN, Ugarte M, Chao M, Chidlow G, Bae JH, et al. 1999a. Neuroprotection in relation to retinal ischemia and relevance to glaucoma. Surv Ophthalmol 43(Suppl1): S102-128. doi: 10.1016/ S0039-6257(99)00044-2

96. Osborne NN, Wood JP, Chidlow G, Bae JH, Melena J, et al. 1999b. Ganglion cell death in glaucoma: what do we really know? $\mathrm{Br} J$ Ophthalmol 83(8): 980-986. doi: 10.1136/bjo.83.8.980

97. Russo R, Rotiroti D, Tassorelli C, Nucci C, Bagetta G, et al. 2009 Identification of novel pharmacological targets to minimize excitotoxic retinal damage. Int Rev Neurobiol 85: 407-423. doi: 10.1016/S00747742(09)85028-9

98. Qu J, Wang D, Grosskreutz CL. 2010. Mechanisms of retinal ganglion cell injury and defense in glaucoma. Exp Eye Res 91(1): 48-53. doi: 10.1016/j.exer.2010.04.002

99. Kowluru RA, Zhong Q. 2011. Beyond AREDS: is there a place for antioxidant therapy in the prevention/treatment of eye disease? Invest Ophthalmol Vis Sci 52(12): 8665-8671. doi: 10.1167/iovs.10-6768

100.Li SY, Fu ZJ, Lo AC. 2012. Hypoxia-induced oxidative stress in ischemic retinopathy. Oxid Med Cell Longev 2012: 426769. doi: $10.1155 / 2012 / 426769$

101. Orrenius S, Zhivotovsky B, Nicotera P. 2003. Regulation of cell death: the calcium-apoptosis link. Nat Rev Mol Cell Biol 4(7): 552-565. doi: $10.1038 / \mathrm{nrm} 1150$

102. Choi DW. 1985. Glutamate neurotoxicity in cortical cell culture is calcium dependent. Neurosci Lett 58(3): 293-297. doi: 10.1016/03043940(85)90069-2

103.Khodorov B. 2004. Glutamate-induced deregulation of calcium homeostasis and mitochondrial dysfunction in mammalian central neurones. Prog Biophys Mol Biol 86(2): 279-351. doi: 10.1016/j pbiomolbio.2003.10.002

104.Nicholls DG. 2004. Mitochondrial dysfunction and glutamate excitotoxicity studied in primary neuronal cultures. Curr Mol Med 4(2): 149-177. doi: 10.2174/1566524043479239

105. Rathnasamy G, Sivakumar V, Rangarajan P,Foulds WS, Ling EA, et al. 2014 $\mathrm{NF}-\kappa \mathrm{B}$ mediated nitric oxide production and activation of caspase-3 cause retinal ganglion cell death in the hypoxic neonatal retina. Invest
Ophthalmol Vis Sci 55(9): 5878-5889. doi: 10.1167/iovs.13-13718

106.Choi JS, Sungjoo KY, Joo CK. 1998. NF-kappa B activation following optic nerve transection. Korean J Ophthalmol 12: 19-24.

107.Tulsawani R, Kelly LS, Fatma N, Chhunchha B, Kubo E, et al. 2010. Neuroprotective effect of peroxiredoxin 6 against hypoxia-induced retinal ganglion cell damage. BMC Neurosci 11: 125 . doi: 10.1186/14712202-11-125

108. Castagné V, Lefèvre K, Clarke PG. 2001. Dual role of the NF-kappaB transcription factor in the death of immature neurons. Neuroscience 108(3): 517-526. doi: 10.1016/S0306-4522(01)00430-4

109. Kaur C, Sivakumar V, Foulds WS, Luu CD, Ling EA. 2012. Hypoxiainduced activation of $\mathrm{N}$-methyl-D-aspartate receptors causes retinal ganglion cell death in the neonatal retina. J Neuropathol Exp Neurol 71(4): 330-347. doi: 10.1097/NEN.0b013e31824deb21

110.Sivakumar V, Foulds WS, Luu CD, Ling EA, Kaur C. 2013. Hypoxiainduced retinal ganglion cell damage through activation of AMPA receptors and the neuroprotective effects of DNQX. Exp Eye Res 109: 83-97. doi: 10.1016/j.exer.2013.01.004

111.Lau A, Tymianski M. 2010. Glutamate receptors, neurotoxicity and neurodegeneration. Pflugers Arch 460(2): 525-542. doi: 10.1007/ s00424-010-0809-1

112.Budd SL, Nicholls DG. 1996. Mitochondria, calcium regulation, and acute glutamate excitotoxicity in cultured cerebellar granule cells. J Neurochem 67(6): 2282-2291. doi: 10.1046/j.14714159.1996.67062282.x

113.Liu X, Kim CN, Yang J, Jemmerson R, Wang X. 1996. Induction of apoptotic program in cell-free extracts: requirement for dATP and cytochrome c. Cell 86(1): 147-157. doi: 10.1016/S00928674(00)80085-9

114.Dugan LL, Sensi SL, Canzoniero LM, Handran SD, Rothman SM, et al. 1995. Mitochondrial production of reactive oxygen species in cortical neurons following exposure to $\mathrm{N}$-methyl-d-aspartate. J Neurosci 15(10): 6377-6388.

115.Ferreira IL, Duarte CB, Carvalho AP. 1996. $\mathrm{Ca}^{2+}$ influx through glutamate receptor-associated channels in retina cells correlates with neuronal cell death. Eur J Pharmacol 302(1-3): 153-162. doi: 10.1016/0014-2999(96)00044-1

116. Coyle JT, Puttfarcken P. 1993. Oxidative stress, glutamate, and neurodegenerative disorders. Science 262(5134): 689-695. doi: 10.1126/ science.7901908

117. Simonian NA, Coyle JT. 1996. Oxidative stress in neurodegenerative diseases. Annu Rev Pharmacol Toxicol 36: 83-106. doi: 10.1146/annurev. pa.36.040196.000503

118.Martin LJ, Brambrink AM, Price AC, Kaiser A, Agnew DM, et al. 2000. Neuronal death in newborn striatum after hypoxia-ischemia is necrosis and evolves with oxidative stress. Neurobiol Dis 7(3): 169-191. doi: $10.1006 /$ nbdi.2000.0282

119.Geiger LK, Kortuem KR, Alexejun C, Levin LA. 2002. Reduced redox state allows prolonged survival of axotomized neonatal retinal ganglion cells. Neuroscience 109(3): 635-642. doi: 10.1016/S03064522(01)00493-6

120.Xu W, Chi L, Row BW, Xu R, Ke Y, et al. 2004. Increased oxidative stress is associated with chronic intermittent hypoxia-mediated brain cortical neuronal cell apoptosis in a mouse model of sleep apnea. Neuroscience 126(2): 313-323. doi: 10.1016/j.neuroscience.2004.03.055

121.Izzotti A, Bagnis A, Saccà SC. 2006. The role of oxidative stress in glaucoma.Mutat Res 612(2): 105-114.doi: 10.1016/j.mrrev.2005.11.001

122.Moreno MC, Campanelli J, Sande P, Sánez DA, Keller Sarmiento MI, et al. 2004. Retinal oxidative stress induced by high intraocular pressure. Free Radic Biol Med 37(6): 803-812. doi: 10.1016/j. freeradbiomed.2004.06.001

123.Tezel G. 2006. Oxidative Stress in Glaucomatous Neurodegeneration: Mechanisms and Consequences. Prog Retin Eye Res 25(5): 490-513. doi: 10.1016/j.preteyeres.2006.07.003 
124.Li SY, Yang D, Yeung CM, Yu WY, Chang RC, et al. 2011. Lycium barbarum polysaccharides reduce neuronal damage, blood-retinal barrier disruption and oxidative stress in retinal ischemia/reperfusion injury. PLoS One 6(1): e16380. doi: 10.1371/journal.pone.0016380

125.Arden GB, Sivaprasad S. 2011. Hypoxia and oxidative stress in the causation of diabetic retinopathy. Curr Diabetes Rev 7(5): 291-304. doi: 10.2174/157339911797415620\#sthash.ij8jQLWI.dpuf

126.Ha Y, Saul A, Tawfik A, Zorrilla EP, Ganapathy V, et al. 2012. Diabetes accelerates retinal ganglion cell dysfunction in mice lacking sigma receptor 1. Mol Vis 18: 2860-2870.

127.Di Lisa F, Bernardi P. 1998. Mitochondrial function as a determinant of recovery or death in cell response to injury. Mol Cell Biochem 184(1-2): 379-391. doi: 10.1007/978-1-4615-5653-4_25

128.Kroemer G, Dallaporta B, Resche-Rigon M. 1998. The mitochondrial death/life regulator in apoptosis and necrosis. Annu Rev Physiol 60: 619-642. doi: 10.1146/annurev.physiol.60.1.619

129.Lemasters JJ, Nieminen AL, Qian T, Trost LC, Elmore SP, et al. 1998. The mitochondrial permeability transition in cell death: a common mechanism in necrosis, apoptosis and autophagy. Biochim Biophys Acta 1366(1-2): 177-196. doi: 10.1016/S0005-2728(98)00112-1

130.Frey T, Antonetti DA. 2011. Alterations to the blood-retinal barrier in diabetes: cytokines and reactive oxygen species. Antioxid Redox Signal 15(5): 1271-1284. doi: 10.1089/ars.2011.3906

131. Fields RD, Burnstock G. 2006. Purinergic signalling in neuron-glia interactions. Nat Rev Neurosci 7(6): 423-436. doi: 10.1038/nrn1928

132.Sanderson J, Dartt DA, Trinkaus-Randall V, Pintor J, Civan MM, et al. 2014. Purines in the eye: recent evidence for the physiological and pathological role of purines in the RPE, retinal neurons, astrocytes, Müller cells, lens, trabecular meshwork, cornea and lacrimal gland. Exp Eye Res 127: 270-279. doi: 10.1016/j.exer.2014.08.009

133. Chavda S, Luthert PJ, Salt PE. 2013. P2X7 receptor activation modulates light-evoked retinal ganglion cell synaptic responses and microglial morphology. Soc Neurosci Abstr 553: 513.
134.Sugiyama T, Oku H, Shibata M, Fukuhara M, Yoshida H, et al. 2010. Involvement of $\mathrm{P} 2 \mathrm{X} 7$ receptors in the hypoxia-induced death of rat retinal neurons. Invest Ophthalmol Vis Sci 51(6): 3236-3243. doi: 10.1167/iovs.09-4192

135. Niyadurupola N, Sidaway P, Ma N, Rhodes JD, Broadway DC, et al. 2013. P2X7 receptor activation mediates retinal ganglion cell death in a human retina model of ischemic neurodegeneration. Investig Ophthalmol Vis Sci 54(3): 2163-2170. doi: 10.1167/iovs.12-10968

136. Hartwick AT, Lalonde MR, Barnes S, Baldridge WH. 2004. Adenosine A1-receptor modulation of glutamate-induced calcium influx in rat retinal ganglion cells. Investig Ophthalmol Vis Sci 45(10): 3740-3748. doi: 10.1167/iovs.04-0214

137. Newman EA. 2005. Calcium increases in retinal glial cells evoked by light-induced neuronal activity. J Neurosci 25(23): 5502-5510. doi: 10.1523/JNEUROSCI.1354-05.2005

138.Zhang M, Budak MT, Lu W, Khurana TS, Zhang X, et al. 2006. Identification of the A3 adenosine receptor in rat retinal ganglion cells. Mol Vis 12: 937-948.

139. Takagi H, King GL, Robinson GS, Ferrara N, Aiello LP. 1996. Adenosine mediates hypoxic induction of vascular endothelial growth factor in retinal pericytes and endothelial cells. Invest Ophthalmol Vis Sci 37(11): 2165-2176.

140.Wiechmann AF. 1986. Melatonin: parallels in pineal gland and retina. Exp Eye Res 42(6): 507-527. doi: 10.1016/0014-4835(86)90042-4

141. Reiter RJ. 1997. Antioxidant actions of melatonin. Adv Pharmacol 38: 103-117. doi: 10.1016/S1054-3589(08)60981-3

142. Kaur C, Sivakumar V,Ling EA.2010. Melatonin protects periventricular white matter from damage due to hypoxia.J Pineal Res 48(3): 185-193. doi: 10.1111/j.1600-079X.2009.00740.x

143.Lee MY, Kuan YH, Chen HY, Chen TY, Chen ST, et al. 2007. Intravenous administration of melatonin reduces the intracerebral cellular inflammatory response following transient focal cerebral ischemia in rats. J Pineal Res 42(3): 297-309. doi: 10.1111/j.1600079X.2007.00420.x 